\title{
“I Say That World May Go To Pot For Me So Long As I Always Get My Tea”: About the Self-Schemas Activation in Social Influence Techniques.
}

\section{Karolina Dobrosz-Michiewicz, University of Lodz, Poland}

\begin{abstract}
Concern for the positive self-image is one of the most important human adaptive traits and affects many of our social behaviors, e.g. related with self-promotion or self-defense (Oleś, 2003, 243). Self-system discrepancy causes negative emotions. To avoid them e.g. in motivational approach/avoidance conflicts, people prefer to choose information congruent with their self-schemas, irrespective of messages rightness or truth (Kofta, Dolinski 2000). Furthermore, the regulatory fit state (between individuals motivational orientation to a goal and the manner in which they pursue the goal) as provided increases the effectiveness of persuasive appeals (Higgins, 2000, 2005, 2007). Study present the results of natural experiment made in July 2013 to verify (1) if it is possible to influence people referring to their self-schemas activation and (2) how to use the self-schemas activation to increase persuasion. In 2 x 2 between subject factorial design, the subjects were influenced in one of four experimental conditions (self-schema activation vs. no activation message-goal congruence: congruent vs incongruent; Higgins 2012a). The results indicate two conclusions: (1) self-schema activation and goal-message congruency increase the level of social influence but the effect of congruency was stronger than self-schema; (2) self-schema activation increases the effect of goal-message congruency.
\end{abstract}

Keywords: social influence techniques, motivational approach/avoidance conflicts, selfschemas activation, regulatory fit 


\section{The Role of Self-Schemas Activation in Social Influence Techniques}

Positive self-image growth is one of the main human adaptive traits as self-conscious individuals and affects our social behaviors, e.g. related with self-promotion or self-defense (Oleś, 2003, 243).Although the ego-system has largely hidden nature or automatic (people know what they feel, what to choose and what conclusions come, but do not know how it happens), it plays a main and significant role in our perception processes focused on constructing and maintaining world and has many implications for our cognition(people treat their own experiences and, derived from them, beliefs about themselves as something personally important, often associated with self-identity) (Pervin 2002) and the motivational functioning (the fourth function of Self: the regulation of aim oriented behaviors) (Wojciszke, 2011: 162). Derived from past experience ego-scripts, organize and direct the processing of current information, evaluated and selected according to their importance for SELF. The tendency to favor information which confirms our SELF schemas and reject those contradict is a natural human trait (Pervin 2002: 254).Tendency to interpret and reinterpret occurring events in relation to and in accordance with SELF is not only the basis for sustaining the positive beliefs of the individual about himself (which is a source of positive emotions), but also maintain the coherence of the whole SELF system (Kofta, Dolinski 2000). The occurrence of discrepancies in the SELF system-nevertheless being a result of which motivational effect (approach vs. avoidance) - is always combined, in the individuals' experience, with negative emotions: depression vs. anxiety (depending on whether there is a discrepancy between the real and ideal SELF or ought and ideal SELF). To minimize negative feelings, people used to reduce discrepancy in SELF system (Higgins, 2012a). This natural tendency to maintain SELF system coherency is successfully used in some social impact techniques, e.g. the induction of hypocrisy technique by E. Aronson, the witness of interaction strategy by B. Rind and D. Benjamin, reciprocity key principle by R. Cialdini, ingratiation strategy by E.E. Jones and T.S. Pittman, the name remembrance effect by D. Howard or the effect of incidental similarity by J.M. Burger. The main condition for the effectiveness of persuasion is in fact feeling right of individuals, which is being persuaded (Cesario, Higgins, Scholer, 2008).

\section{How Regulatory Fit Can Influence On Consumers Submission by Persuasive Messages}

The concept of regulatory fit is derived from the E. Tory Higgins model of regulatory focus (regulatory focus theory) and goes back to his cognitive theory of personality, known as the 
self-discrepancy theory (Higgins 2012B). According to Higgins, in the SELF system coexist two types of standards (self - guidance): ideal and ought SELF. The former is cognitive representation of SELF which a person would like to be, associate with hopes, dreams, wishes and ambitions concerning himself. It develops as a result of experiencing the presence or absence of positive states - for example when being or not rewarded. Success appears when positive state is achieved, but failure appears when positive state is NOT achieved. The latter is cognitive representation of SELF which a person should be, related to the categories of duty and responsibility. Ought SELF develops as a result of experiencing the presence or absence of negative states - such as punishment or lack of punishment. Success means avoidance of negative state and failure means his presence. Failure ideals and frustration associated with growth needs (nurturance needs) is related - for the individuals - with the experience of negative emotions: depression and sadness. Failure to meet obligations and frustration associated with security needs- the experience of anxiety.

Both: ideal SELF and ought SELF are desirable states, discrepancy of them - not. The selfsystem discrepancy reduction can be done in two ways: through the processes of desire and/or avoidance of the goal important to achieve by individuals. Striving for compliance with the state is desirable strategy more typical for promotionally oriented individuals (promotion regulatory focus) while avoiding non-compliance with the state desired - for targeted preventive (prevention regulatory focus). Both systems of self-regulation (orientation promotional and preventive orientation) operate in parallel, are distinct one from the other and independent. The activity and/or the dominance of these two orientations, one or even none of them are possible. What is important, Higgins by regulatory focus understand both: the inherent characteristic of the individual, personality variables and situational factors. It is possible to influence people referring to individual differences in chronic activity of the specific orientation (as a result of chronic cognitive accessibility of ideal/oughtself) or by situational factors that increase availability of cognitive specific standard at present moment.

To measure regulatory focus, understood as a variable of personality, Higgins created two methods: measuring the relative strength of the regulatory standards, operationalized as individual differences in the chronic accessibility of ideals vs. duties and regulatory focus questionnaire, which items refer to a subjective history of effective promotion vs. prevention acts of self-regulation. 
When the goal achievement method and individual's regulatory orientation (regardless of whether it is the inherent characteristic or is primed by the situational context) are coherent it means we have regulatory fit conditions (Higgins, 2000). Promotionally oriented individuals achieve their goals with the method of eagerness (eagerness means), through the pursuit of positive states and avoiding their absence. Preventively oriented individuals achieve their goals with using the method of vigilance (vigilance means), through the pursuit of noncompliant states with negative states and their avoidance (careful to avoid all possible mistakes). When a promotionally focused person works in eager method or preventively focused person in the method of vigilance, it means we have regulatory fit state. The research results indicate that regulatory fit between the goal and orientation of the individuals, not only affects some cognitive functions (better memory, greater concentration of attention) in a situation of regulatory fit; Aaker and Lee, 200) or decision making processes (more positive assessment, when decision making and its implementation is characterized by higher regulatory fit; Freitas, Higgins 2002), but also moderates the assessments of the evaluated objects (we value higher objects that have been selected with higher regulatory fit ; Higgins, Idson, Freitas, Spiegel, Molden 2003).

Moreover, in a situation of regulatory fit targeting, individuals with situational factors primed contextually, e.g.: the content of communication (promotionally vs. preventively oriented information about the object (Aacker, Lee 2001)); character of the model (positive vs. negative character (Lockwood, Jordan, Kunda 2002)), nature of arguments (promotion vs. preventive arguments (Cesario, Grant, Higgins 2004)), language (abstract vs. concrete; Semin, Higgins, de Montes, Estourget, Velencia 2005)), the purpose of the message (promotion vs. prevention; Higgins 2006) or action (approach vs. avoid Spiegel, 2004), and even verbal and nonverbal aspects of communication (promotional or preventively oriented gestures and facial expressions (Cesario, Grant, Higgins 2004)) increase the effectiveness of persuasion. Scott Spiegel (2004) proved that larger regulatory fit between message (on different levels) and the orientation of message can increase the persuasive message influence understood as the ability to do what we asked about. In Spiegel's experiment the subjects first: received the booklets showing the benefits of eating fruits and vegetables (in one experimental group the arguments were presented in the language of prevention, in the other of promotion), and after: about different purpose of keeping a diet rich in fruits and vegetables (in one experimental group the aim was focused on the benefits resulting from 
eating these products and in the other - focused on the consequences of their refusal of eating fruits and vegetables). All participants of the experiment were asked also - for one week- to enroll in the diaries of what they eat during this time. People, who were induced promotionally, ate more vegetables and fruits, when the purpose of their actions was provided in the form of a performance benefit than when it was presented in the language of loss. The person who make focus on prevention, eat more fruits and vegetables, when the target is shown in terms of avoiding losses than enjoyment. So if the situation in which the recipient of the message is subjected to persuasion could be a "trigger condition" for his feeling right state (to maintain or raise his self-esteem), how we can use SELF-scripts activation in social influence? Whether and how it affects the effectiveness of persuasive interactions?

\section{Research Method and Experimental Procedure}

The main aim of the study was to determine the role of the SELF-scripts activation (means as being self-centered by the message) in the effectiveness of persuasive messages in regulatory fit conditions between the promotional regulatory focused individuals and congruent vs. incongruent with that goal-message conditions (goal-message congruency vs. goal-message incongruency).

To find the answer for three research questions:

- does the SELF-scripts activation (as the content of the message) increases the effectiveness of its persuasion (means as succumbing to the influence) in goal-message congruency conditions?

- does the SELF-scripts activation (as the content of the message) increases the effectiveness of its persuasion (means as succumbing to the influence) in goal-message incongruency conditions?

- does the SELF-scripts activation in goal-message congruency vs goal-message incongruency conditions differentiate the level of persuasion effectiveness?

two research hypotheses were verified:

$\mathrm{H}_{1}$ : SELF-scripts activation (as the content of the message) increases effectiveness of persuasion both in goal-message congruency vs goal-message incongruency conditions. $\mathrm{H}_{2}$ : The effectiveness of persuasion induced by SELF -scripts activated messages is higher in goal-message congruency than in goal-message incongruency conditions.

The subjects of $2 \times 2$ between subject factorial design experiment (self-schema activation vs. no $\mathrm{x}$ message-goal congruence: congruent vs incongruent; the order of 
occurrence in this four conditions was random) were 120 adult males (64) and female (56) passersby in main streets in the center of the city (Łódź; Poland), mostly young, in their 20s and early 30 s.

The confederate: 25 years old woman approached passersby to sign the petition advocating a create and enter traffic calming program in Łódź. She introduced herself and interest group for whom he was supposedly working and the traffic calming idea in ,promotional” way: „We are a group named Green City, who had approached the city government to argue for creating and entering the traffic calming program to improve safety and live quality on central residential streets" and influenced recipients in one of four messages, in four different conditions:

1. in goal-congruent message and self-schema activation condition she went on stress the positive outcomes, stating that: if the traffic calming program enters into force, your safety, your comfort and your mobility for non-motorized travel certainly will improve

2. ingoal-incongruent message and SELF-schema activation condition, the confederate's statement stressed the adverse affect of not attaining the goal, stating that: if the traffic calming program does not enter into force, your safety, your comfort and your mobility for no-motorized travel certainly will not improved

3. in goal-congruent message and no SELF-schema activation condition she went on stress the positive outcomes, stating that: if the traffic calming program enter into force, road safety, comfort and mobility for non-motorized travel in the city certainly will improve"

4. in goal-incongruent message and no SELF-schema activation condition, the confederate's statement stressed the adverse affect of not attaining the goal, stating that: if the traffic calming program does not enter into force, road safety, comfort and mobility for non-motorized travel in the citycertainly will not improve”

Dependent variable in this model was: decision made by recipient's means as responses on five points Likert scale (evidence of social influence). Independent variables were: selfschema activation and goal-message congruency. Agreed to „create and enter the traffic calming program" was given by recipients on five-level Likert items, represented as follows:

- strongly disagree (1)

- disagree (2) 
- neither agree nor disagree (3)

- agree (4)

- strongly agree (5)

Regardless of whether the target fulfilled 1 or 5 , all participants were thanked for their time and interest.

\section{Results and Conclusions}

Null hypothesis of equal variances is rejected for: Constant + Self - schema + Congruency + Self - schema*Congruency in 4 groups. Levene's test (table 1) for dependent variable: DECISION confirmed the correctness of selected model.

\section{Table 1.Levene's Test}

Results of analysis of variance (table 2) for two independent variables indicate that both: SELF-activation and goal-message congruency increase the effectiveness of persuasive messages. Moreover, the effect caused by regulatory fit is stronger (at the level of statistical significance, 002) than the effect of recipients self-schema activation (statistical significance level, 056). Both assumptions $\left(\mathrm{H}_{1}\right.$ : SELF-scripts activation increases effectiveness of persuasion both in goal-message congruency vs goal-message incongruency conditions, $\mathrm{H}_{2}$ : The effectiveness of persuasion induced by SELF-scripts activated messages is higher in goalmessage congruency than in goal-message incongruency conditions) were confirmed.

Table 2.Effect Tests between objects for dependent variable: decision 
All Experimental conditions divided participants into four groups:

- 1 st group - self -schema activation and g-m congruence condition

- 2nd group - self -schema activation and g-min congruence condition

- 3rd group - no self -schema activation and g-m congruence condition

- 4th group - no self -schema activation and g-m incongruence condition

To look for further interactions outcomes were analyzed by post hoc Tuckey test (table 3.). Two Interactions between 1st and 4th groups and 3rd and 4th support results from ANOVA.

Table 3. Mulitiple comparsion, Tuckey Test

\begin{tabular}{|c|c|c|c|c|c|c|c|}
\hline & \multirow[t]{2}{*}{ (I) groups } & \multirow[t]{2}{*}{$(\mathrm{J})$ groups } & \multirow[t]{2}{*}{$\begin{array}{c}\text { Mean } \\
\text { difference } \\
(\mathrm{I}-\mathrm{J})\end{array}$} & \multirow[t]{2}{*}{ SD } & \multirow[t]{2}{*}{$\underset{\text { value }}{\mathrm{p}-}$} & \multicolumn{2}{|c|}{$95 \%$ Confidence } \\
\hline & & & & & & $\begin{array}{c}\text { The lower } \\
\text { limit }\end{array}$ & $\begin{array}{c}\text { The upper } \\
\text { limit }\end{array}$ \\
\hline $\begin{array}{l}\text { Tuckey } \\
\text { Test }\end{array}$ & $1 \mathrm{st}$ & 2 nd & ,50000 & ,31738 & ,397 &,- 3273 & 1,3273 \\
\hline & & $3 \mathrm{rd}$ & ,23333 & ,31738 &, 883 &,- 5940 & 1,0606 \\
\hline & & 4th & 1,13333(* & 31738, & ,003 & ,3060 & 1,9606 \\
\hline & 2nd & $1 \mathrm{st}$ &,- 50000 & ,31738 & ,397 & $-1,3273$ & ,3273 \\
\hline & & $3 \mathrm{rd}$ &,- 26667 & ,31738 &, 835 & $-1,0940$ & ,5606 \\
\hline & & 4 th & 63333 & ,31738 & , 196 &,- 1940 & 1,4606 \\
\hline & $3 r d$ & $1 \mathrm{st}$ &,- 23333 & 31738 & ,883 & $-1,0606$ & ,5940 \\
\hline & & 2nd & 26667 & ,31738 &, 835 &,- 5606 & 1,0940 \\
\hline & & 4th &, $90000(*)$ & 31738 & ,027 & ,0727 & 1,7273 \\
\hline & 4th & 1st & 1,13333(* & 31738 & ,003 & $-1,9606$ &,- 3060 \\
\hline & & 2nd &,- 63333 & ,31738 & , 196 & $-1,4606$ & 1940 \\
\hline & & 3rd & ,90000(*) & 31738 & ,027 & $-1,7273$ &,- 0727 \\
\hline
\end{tabular}

* Significant differences .05 .

There is no interaction between the two independent variables: the activation of SELF schemas and regulatory fit experimentally primed. It may be either the result of applying a simplified, limited only to the regulatory fit condition experimental plan (it is recommended to check whether both effects will be observable if the above test will be executed in scheme 2 x 2 x 3; to introduce traffic calming idea in ,prevention” way) or nondichotomous character of dependent variable (it is recommended to change the scaling possibility as a sigh of 
decision making of respondents for only YES or NO answer, confirmed by recipients donation of funds for the implementation of traffic calming program) or maybe even individualized understanding of "comfort" and "security" or "withdrawal" as the main activators regulatory focus exclusively promotional or preventive (it is recommended to make - after experimental priming - measurements of individuals chronic regulatory focus by RFS and/or RFQ and analyze the covariance results). Further research is required also into the role of self-activation including the impact of variables such as collectivism/individualism or whether public/private SELF -image. 


\section{References}

Bąk W. (2008). Teoria ukierunkowań regulacyjnych E. Tory Higginsa, Roczniki Psychologiczne, 9, 1.

Cesario J. F.,GrantH,m Higgins E.T. (2004). Regulatory fit and persuation: transfer from feeling right. Journal of Personality and Social Psychology, 86.

Cesario J. F., Higgins E.T., Scholer A.A. (2008). Regulatory fit and persuation: Basic principles and remaining questions. Social and Personality Psychological Compass, $2 / 1$.

Doliński D. (2011). Techniki wpływu społecznego. Warszawa: Wydawnictwo Naukowe Scholar.

Doliński D., Drogosz M. (2007). Czy obywatele poszliby głosować przeciw? Regulacyjne nastawienie na promocję vs prewencję a aktywność wyborcza. Kolokwia psychologiczne, 16.

Freitas A.L, Higgins E.T (2002). Enjoying goal-direction action: The role of regulatory fit.Psychological Science, 13.

Higgins E.T (2000). Making a good decision: Value from fit.American Psychologist, 55.

Higgins E.T. (2006). Value from hedonic experience and engagement.Psychological Review, 113.

Higgins E.T. (2012a). Regulatory fit focus, Handbook of theories of social psychology. Higgins E.T. (2012b). Accesability theory, Handbook of theories of social psychology. Kofta M., Doliński D. (2000). Poznawcze podejście do osobowości, w: J. Strelau (red.) Psychologia. Podręcznik akademicki (t.2). Gdańsk: Gdańskie Wydawnictwo Psychologiczne.

Lee A.Y., Aaker J. L. (2004). Bringing the Frome into focus: The influence of regulatory fit on processing fluency and persuation.Journal of Personality and Social Psychology, 86.

Lockwood P., Jordan C.H., Kunda Z. (2002). Motivation by positive or negative role models: Regulatory focus determines who will best inspire us, Journal of Personality and Social Psychology, 83.

Oleś P. K. (2003). Wprowadzenie do psychologii osobowości. Warszawa: Wydawnictwo Naukowe Scholar.

Pervin L.A. (2002). Psychologia osobowości. Gdańsk: Gdańskie Wydawnictwo Psychologiczne. 
Semin G.R, Higgins T., de Montes L.G., Estourget Y, Valencia J.F. (2005). Linguistic signatures of regulatory focus: How abstraction fits promotion more than prevention. Journal of Personality and Social Psychology, 89.

Spiegel S., Grant-Pillow H., Higgins E. T. (2004). How regulatory fit enhances motivational strenght during goal pursuit. European Journal of Social Psychology, 34.

Wojciszke B. (2011). Psychologia społeczna. Warszawa: Wydawnictwo Naukowe Scholar. 